\title{
Get It in Writing: MOUs and Library/IT Partnerships
}

\begin{abstract}
Purpose: Increasingly academic libraries are partnering with other campus units to improve efficiency and to better serve students and faculty. This paper focuses on the importance of developing a memorandum of understanding (MOU) to foster a relationship between an academic library and IT unit. It identifies what the MOU should include, pitfalls to be avoided, and lessons learned. It also demonstrates how the MOU has been used as a model for other alliances and how, because of the MOU, a partnership has flourished.
\end{abstract}

Design/methodology/approach: This article will outline the steps taken that led to the successful memorandum of understanding (MOU) created by the Indiana University Bloomington (IUB) Libraries and University Information Technology Services (UITS.)

Findings: A well crafted memorandum of understanding that allows for flexibility in ongoing decision making by service stakeholders permits partnerships to evolve and mature and creates the avenue for continued success and innovation.

Practical implications: This paper describes the execution and ongoing evolution of a successful partnership based on a MOU and commitment by the Indiana University Bloomington (IUB) Libraries and the central technology organization, University Information Technology Services (UITS).

Originality/value: Libraries interested in entering into or strengthening partnerships with IT or other campus organizations can use the Indiana University experience and MOU as a model.

Keywords: academic libraries, information technology, information commons, memorandums of understanding, MOU, partnerships

Paper Type: General review

\section{Introduction}

"The romance of courtship quickly gives way to the day-to-day reality as partners begin to live together. Joint ventures are also new ventures and are thus fraught with uncertainty and unanticipated roadblocks. Now more than the upper echelons of management must work together to make the partnership succeed." (Kanter, 103-104)

This is especially true for academic libraries that are partnering with other campus units to increase efficiency and better serve students and faculty. Many of these partnerships require non-library units to occupy library space or to employ library services and resources. Developing and executing a memorandum of understanding (MOU) before beginning any joint venture can set expectations, foster cooperation, delineate the governance structure of the partnership, and ensure the successful delivery of services. 
The most prominent and successful example of an IT and Library partnership at Indiana University is the Information Commons. The MOU provides the ongoing framework of this relationship.

\section{Background}

Founded in 1820, Indiana University is a nine campus public university system with a total of 922 authorized degree programs, over 92,000 students, and 16,000 faculty and staff. Nestled in the rolling hills of southern Indiana, the main campus, often referred to as Indiana University Bloomington or IUB, enrolls 37,958 students and conferred 8,590 degrees last year.

On the Bloomington campus, the Herman B Wells Library, with its two towers of Indiana limestone, is the visual center of a system that includes 14 branch libraries and the Lilly Library of rare books and manuscripts. The collections include more than 6.6 million volumes in over 900 languages with an emphasis on the humanities and social sciences. The IUB Libraries rank $12^{\text {th }}$ among the member libraries of the Association of Research Libraries. An Information Commons occupies more than 36,000 square feet over two floors in the west tower of the building, formally the Undergraduate Library.

University Information Technology Services (UITS) at Indiana University, with offices on the Bloomington and Indianapolis campuses, develops and maintains a modern information technology environment throughout the university in support of IU's vision for excellence in research, teaching, outreach, and lifelong learning. UITS provides tools and services to support the academic and administrative work of the university, including a high-speed campus network with wireless access, central web hosting, a rich selection of free and low-cost software for personal use, tools and support for instruction and research, and supercomputers for data analysis and visualization.

Administratively, the IUB Libraries are separate from UITS. However, the Libraries and UITS have had a successful history of working together before planning for the Information Commons in 2001. Examples include:

- The Digital Library Program (DLP), launched in 1997, is a partnership between the Libraries, UITS, and the School of Library and Information Science.

- The Assistant Dean of Library Information Technology is a joint appointment with UITS.

- In the early 1990's space was given to UITS, first for a 24 hour Student Technology Center, and later on two other STCs

\section{Developing the Partnership}

In her Harvard Business Review article, "Collaborative Advantage: The Art of Alliances," (July/August 1994), Rosabeth Moss Kanter's research fines "three fundamental aspects of business alliances" that can be applied to library-IT partnerships.

- "They must yield benefits for the partners, but they are more than just the deal. They are living systems that evolve progressively in their possibilities. Beyond the immediate reasons for entering into a relationship, the connection offers the parties an option on the future, opening new doors and unforeseen opportunities.

- Alliances that both partners ultimately deem successful involve collaboration, (creating new value together) rather than mere exchange (getting something back for what you put in). Partners value the skills each brings to the alliance. 
- They cannot be "controlled" by formal systems but require a dense web of interpersonal connections and internal infrastructures that enhance learning." (Kanter, 1994)

During the 1990's, the IUB Libraries created the foundation for the partnership when space in the Wells Library was given to UITS to install STCs. Even though the technology organization began providing services in the library the operations of UITS and Library staff were still quite separate. Since then, the development and growth of the IC has spawned a partnership that is the envy of many higher education institutions.

The Information Commons "yields benefits" for both the Library and UITS because individually these organizations could only provide components of an Information Commons. The "new value" created by this partnership is represented by the suite of combined Library and IT services available to students in a new, inviting and comfortable space. The success of this partnership can be measured by gate counts, computer login statistics, and information collected from student surveys. "A dense web of interpersonal relationships" now exists between several layers of the Library and UITS.

The IC MOU provides the framework for partnership, manages the engagement, ensures the commitment of ongoing resource allocation, and last but not least serves as the model for subsequent successful partnerships.

\section{Development of the IC and its components}

In 1999, the vision of an Information Commons was conceived through a shared commitment to student engagement and access to library and IT resources. Recognition of the need for access to physical resources led to funding and resource commitments by the Bloomington campus, the IUB Libraries, and UITS. The result was the construction of an "Information Commons" in the IUB Wells Library. As a partnership of UITS and the IUB Libraries, the IC, designed as a central meeting ground equipped with state-of-the-art IT and library services and resources, became host to individual and collaborative work areas 24/7/360.

The methodology included identifying key operational stakeholders who would provide services and support in the new facility. These stakeholders became the members of the steering committee that would guide design, management and commitment of resources, selection of furnishings, signage, and renovation of the space. The first task was to craft and agree to guiding principles. Those principles included:

- Leveraging existing service, support, and management models.

- Incorporating existing account and identity management models and business practices into business processes.

- Reinforcing existing technical infrastructure.

- Providing service options to suit needs.

- Establishing a governance committee to guide short term and long term strategic planning and operational processes and procedures.

These guiding principles became the foundation for a web of personal interaction between Library and UITS staff much like two families arranging a betrothal. This communication further galvanized the alliance and potential for success. 


\section{Why an MOU?}

As operating practices and procedures began to formulate around the guiding principles the stakeholders recognized the importance of documenting the ongoing rules of engagement. A desire by both the Library and UITS for the partnership to evolve and grow led to the decision to create an MOU. In order to ensure acceptance and thoroughness, administrative and operational stakeholders were engaged in early discussions about crafting the MOU.

One of the first MOU components identified as critical was the commitment to regularly review and modify the MOU, thus dictating a document design permitting flexibility and evolution; especially for day to day joint operations. For example, as services and technologies change, service delivery, business practices, and support advance accordingly. Maintaining a current and relevant MOU further ensures long term success.

The Library and UITS MOU provides stability and guarantees the partnership will last beyond the tenure of those involved in launching the alliance. It also establishes: expectations for service levels, ongoing financial commitments with funding for upgrades and life cycle maintenance of the facility and technology, continuing human resource commitments; and a documented shared vision for continued exceptional library and IT service.

\section{MOU Components}

The following key MOU components were derived from the essential strengths and services and in-kind and monetary commitments the IUB Libraries and UITS brought to the alliance:

Vision statement - provides the conceptual view of the partnership goal(s). Guiding principle(s) - supplies the common ground for rules of engagement. Partnership and alliance definition(s) - satisfies the need for well defined partnership roles and responsibilities and further develops the rules of engagement.

Services and resources - build on the range of unique talent and expertise and formalize joint resource commitments while further detailing the list of contributions from the partners.

Governance and management - clarifies and constitutes accountability for management of staff, resources, and services.

Funding - commits short-term, start-up costs; and guarantees commitment for long term funding, replacement of equipment, and continued staffing.

Communication and marketing - develops internal and external references and publicity that acknowledge the partnership including signage, marketing materials, web sites, and press releases.

Review process - includes joint and regular review of effectiveness and appropriateness of service offerings, facility maintenance, facility and human resource management, and success in attaining goals accomplished through regular meetings, surveys, and annual review of the MOU.

Annual report - provides stakeholders a review of the year's activities from a fiscal and partnership perspective, including metrics to indicate successes and failures and a list of contributions made by each of the partners.

\section{Lessons Learned}

The MOU is the foundation for several thriving alliances between the IUB Library and UITS. While the instrument and process for creating MOUs has been very successful, 
lessons have been learned along the way. The experiences between the IUB Libraries and UITS have cultivated recognition and appreciation for the elements of the MOU that are vital as well as elements that are better left out.

It is possible for stakeholders with an exciting vision to overstate the possibilities for achievement; therefore, creating the MOU that can evolve in a way that serves the vision of the stakeholders and permits the practical application of business processes is important. Conversely, operational staff with differing cultures may believe detail is essential to defining rules of engagement. While detail is very important, too much detail can be crippling and lend the MOU incapable of flexibility and evolution. Addressing cultural differences is especially important because doing so can help operational staff develop appreciation for each other and find new value in working together.

The flexible design of the MOU empowered staff to feel comfortable establishing an operations group to support the day-to-day activities of the IC. The group has been able to create new business practices within the structure of the original MOU. Shortly thereafter, the IC2 was designed, funded, and opened as an extension of the IC under the existing MOU.

Additionally, providing equal opportunity for partners to achieve equity in the partnership will stimulate communication and sharing. The MOU can ensure the partnership is balanced, fair, and evenhanded. Annual review of commitments, operating practices, and periods of renewal are vital to the health of the MOU and the partnership. In addition to assessing effectiveness and attainment of goals, the annual review permits stakeholders to adjust strategies, resources, and celebrate success.

For IUB Library and UITS, the most important aspect of the MOU has been the commitment to establish a governance committee with regularly scheduled meetings. This commitment has further strengthened the relationships between administrators and staff and permitted the emergence of a new culture.

\section{Expansion of concept to other partnerships}

Because there is a significant and documented shortage of academic space on the Bloomington campus, the libraries are often approached by other campus units with proposal for the use of library space. The Libraries recently developed a set of principles for considering partnerships and/or use of library space by non-library units. The principles include a statement on MOUs: "A Memorandum of Understanding will be written and executed when the Libraries agree to partner with and/or provide space for campus organizations or other service providers. The agreement will include a sunset period to allow for periodic review of the partnership."

Since the IC was developed, the Libraries have written and executed three MOUs. These are for the:

1. W302 Classroom operation: Defines the parameters for Library/IT Training sharing of a training classroom located in the Wells Library,

2. Former School of Library and Information Science (SLIS) Library: Following the mutual agreement to close the SLIS Library, the MOU formally defines which spaces are retained by the library and which revert to SLIS.

3. Ethnomusicological Video for Instruction and Analysis (EVIA) and the College of Arts and Sciences: Defines the space EVIA will occupy in the Wells 
Library, the services EVIA will offer and the source of funding for any renovation costs.

All Library MOUs define the partners, the source of funding, signage, how the service and staff will be listed on library web pages, and issues related to building access, security, and liability.

Biannually the Executive Associate Dean of Libraries convenes a meeting of Wells Library tenants. The purpose of the meetings is to increase communication and discuss issues of concern to staff and units that reside in the Wells Library, but do not report administratively to the Dean. Recent agendas have included discussion about emergency contacts for each unit, reporting building problems, reserving meeting space, signage (including service point hours), and emergency procedures.

\section{Conclusion}

Based on their experiences with a shared library/IT service point, McKinstry and McCracken write from the library perspective that "Communication between the computing and library culture is often a challenge. Both cultures think that they are communicating, but styles and timing are often very different. We have tended to ignore behavior that we would not allow from our own student employees, like leaving backpacks on the floor behind the desk, or not always making sure that the consultant has fully solved the student's problem. These behaviors often go unmentioned for fear of appearing too critical of our partners. We are not too sure which of our behaviors irritate the student computing consultants, but we expect that they exist." (McKinstry, 2002)

While an MOU cannot be expected to address all problems, it can define the communication and governance mechanisms necessary to discuss and solve them. The IUB Libraries and UITS have realized a partnership that has created new value for the university and for students who use the services provided through a fresh approach and new culture that is sustained through communication and a well architected MOU.

So, what does the future hold? The success of each MOU and the trust that continues to grow is paving the way for future projects and partnerships. Developing the MOU has given university administration a sense of confidence regarding the IUB Libraries' ability to deliver value in new ways and to recognize opportunities for partnership that leverage the university's assets. Work has begun on developing the concept of a "Research Commons" with services for faculty and graduate students. A memorandum of understanding will provide the structure for the partnership with UITS and the Office of the Vice Provost for Research for the design of the Research Commons. 


\section{References}

Kanter, R. M. (1994), "Collaborative advantage: the art of alliances", Harvard Business Review, Vol. 72 No 4, pp. 96-108.

McKinstry, J. and McCracken, P. (2002), "Combining computer and reference desks in an undergraduate library: a brilliant innovation or a serious mistake?" portal: Libraries and the Academy, Vol. 2 No. 3, pp. 391-400.

\section{Further Reading}

Dallis, D. (2007) Indiana University Bloomington Information Commons, Indiana University Libraries, available at: www.ic.indiana.edu.

Dallis, D. and Walters, C. (2006), "Reference services in the commons environment", Reference Services Review, vol. 34 no. 2, pp. 248-260.

University Information Technology Services. (2007), www.uits.iu.edu. 